\title{
Colloids: Incredible Particles with Plausible Biomedical and Agro-Environmental Applications
}

\author{
Sai Murali RS* and Uma Maheswari RS \\ Department of Research and Development, India \\ *Corresponding author: Sai Murali RS, Department of Research and Development, GT Road, NH-1, Phagwara, Punjab-144411, India
}

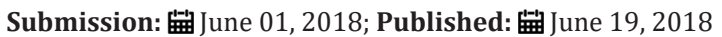

\section{Mini Review}

Scientific and technological advancements of the contemporary world are bewildering. Coping up with the growing needs and changing trends, exploration of new materials for various applications seem to be inevitable. With the promising future in both medicine and environment; nanoparticles, composites and related surrogates are put to wide use in research arena [1] Right from the deployment of various biodegradable materials in molecular and clinical medicine to providing efficient adsorbents in environmental detoxification processes, Nano-world is defining the course of the future [2].

The concept of nano-molecular machines in the recent years has revolutionized the way we deliver drugs to cells and tissues [3]. Nanomaterials are also used as synthetic replacements for biological tissues [4]. The diagnostics and array technologies have been influenced by nano-interventions for the betterment of clinical landscape [5]. Nanomaterials are used in point-of-care technologies for molecular diagnostics with unbelievable levels of precision [6]. The fluorescent biological labels designed out of semiconductor colloidal nanocrystals have exceptional photo-physical properties and versatile medical applications [7,8]. In the cardiac repair, diligently engineered nanoparticles are fabricated on biological macromolecular composites and used in tissue engineering [9]. With the unique intrinsic properties vested on gold nanoparticles, they are put to wide biomedical applications [10-12]. However, Zinc oxide and silver nanoparticles are also equally explored in this regard $[13,14]$. Nanomaterials can also be used in precision farming and sustainable agriculture [15]. Despite the wide applications of various nanoparticles in biomedical and environmental applications, toxicity is a major subject matter for much debate $[1,15,16]$. There is only handful of toxicological reports on nanoparticles on humans and environment. Dearth of information pertaining to toxicity of nanomaterials leaves considerable room for further assessments with every breakthrough.

With the advent of graphene in nanotechnology, the paradigm has shifted with incredible possibilities and efficient processes [17].
Metaphorically regarded as the 'Cinderella of Nanotechnology', Graphene holds promise for next generation biomedical and agroenvironmental technologies [18-20]. Environmental detoxification by nanomaterials is a growing field with plausible opportunities [21]. The scope of this field is to remediate pollutants based on technologies comprising nanoparticles, nanocomposites and other colloids [22,23]. Further, there are possibilities of widening the horizons by developing fusion technologies built on supramolecular chemistry, biomaterials and semiconductors $[24,25]$.

\section{References}

1. Corsi I, Nielsen MW, Sethi R, Punta C, Torre CD, et al. (2018) Ecofriendly nanotechnologies and nanomaterials for environmental applications: Key issue and consensus recommendations for sustainable and ecosafe nanoremediation. Ecotoxicol Environ Saf 154: 237-244.

2. Sridharan K (2018) Emerging trends of nanotechnology in environment and sustainability: a review-based approachm Springer, Germany.

3. Hu Q Li H, Wang L, Gu H, Fan C (2018) DNA nanotechnologyenabled drug delivery systems. Chemical reviews, DOI: 10.1021/acs. chemrev.7b00663.

4. Aldini NN, Fini M (2018) Advances in nanotechnologies for the fabrication of silk fibroin-based scaffolds for tissue regeneration, in extracellular matrix for tissue engineering and biomaterials. Springer, pp. 151-160.

5. Jain KK (2017) Nanomolecular Diagnostics. Handbook of Nanomedicine, Springer, Germany, pp. 133-200.

6. Syedmoradi L, Daneshpour M, Alvandipour M, Gomez FA, Hajghassem H (2017) Point of care testing: the impact of nanotechnology. Biosensors and Bioelectronics 87: 373-387.

7. Zdrojewicz Z, Waracki M, Bugaj B, Pypno D, Cabała K (2015) Medical applications of nanotechnology. Postepy Hig Med Dosw (Online) 69: 1196-1204.

8. Abbasi E, Kafshdooz T, Bakhtiary M, Nikzamir N, Nikzamir N (2016) Biomedical and biological applications of quantum dots. Artificial cells, nanomedicine, and biotechnology 44(3): 885-891.

9. Liu N, Chen J, Zhuang J, Zhu P (2018) Fabrication of engineered nanoparticles on biological macromolecular (PEGylated chitosan) composite for bio-active hydrogel system in cardiac repair applications. Int J Biol Macromol, DOI: 10.1016/j.ijbiomac.2018.04.196. 
10. Khan MS, Vishakante GD, Siddaramaiah H (2013) Gold nanoparticles: A paradigm shift in biomedical applications. Adv Colloid Interface Sci 199200: 44-58.

11. Elahi N, Kamali M, Baghersad MH (2018) Recent biomedical applications of gold nanoparticles: A review. Talanta 184: 537-556.

12. Lu F, Doane TL, Zhu JJ (2012) Gold nanoparticles for diagnostic sensing and therapy. Inorganica Chimica Acta 393: 142-153.

13. Mirzaei H, Darroudi M (2017) Zinc oxide nanoparticles: Biological synthesis and biomedical applications. Ceramics International 43(1, Part B): 907-914.

14. Mishra PK, Mishra H, Ekielski A, Talegaonkar S, Vaidya B (2017) Zinc oxide nanoparticles: a promising nanomaterial for biomedical applications. Drug Discovery Today 22(12): 1825-1834.

15. Iavicoli I, Leso V, Beezhold DH, Shvedova AA (2017) Nanotechnology in agriculture: opportunities, toxicological implications, and occupational risks. Toxicology and Applied Pharmacology 329: 96-111.

16. Parisi C, Vigani M, Cerezo ER (2015) Agricultural nanotechnologies: what are the current possibilities? Nano Today 10(2): 124-127.

17. Zhong Y, Zhen Z, Zhu H (2017) Graphene: fundamental research and potential applications. FlatChem 4: 20-32.

18. Olszowska K, Pang J, Wrobel PS, Zhao L, Ta HQ et al. (2017)Threedimensional nanostructured graphene: Synthesis and energy, environmental and biomedical applications. Synthetic Metals 234: 5385.
19. Foo ME, Gopinath SCB (2017) Feasibility of graphene in biomedical applications. Biomedicine \& Pharmacotherapy 94: 354-361.

20. Sandhya PK, Jose J, Sreekala MS, Padmanabhan M, Kalarikkal N, et al. (2018) Reduced graphene oxide and $\mathrm{ZnO}$ decorated graphene for biomedical applications. Ceramics International, DOI: 10.1016/j. ceramint.2018.05.143.

21. Tratnyek PG, Johnson RL (2006) Nanotechnologies for environmental cleanup. Nano Today 1(2): 44-48.

22. Zhao X, Liu W, Cai Z, Han B, Qian T, et al. (2016) An overview of preparation and applications of stabilized zero-valent iron nanoparticles for soil and groundwater remediation. Wat Res 100: 245-266.

23. Khin MM, Nair AS, Babu VJ, Murugana R, Ramakrishna S (2012) A review on nanomaterials for environmental remediation. Energy \& Environmental Science 5(8): 8075-8109.

24. Ariga K, Ishihara S, Abe H, Lia M, Hill JP (2012) Materials nanoarchitectonics for environmental remediation and sensing. Journal of Materials Chemistry 22(6): 2369-2377.

25. Potara M, Focsan M, Craciun AM, Botiz I, Astilean S (2018) Polymer-coated plasmonic nanoparticles for environmental remediation: Synthesis, functionalization, and properties, in New Polymer Nanocomposites for Environmental Remediation, pp. 361-387.
Creative Commons Attribution 4.0 International License

For possible submissions Click Here

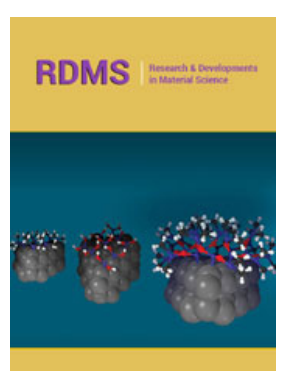

Research \& Development in Material Science

\section{Benefits of Publishing with us}

- High-level peer review and editorial services

- Freely accessible online immediately upon publication

- Authors retain the copyright to their work

- Licensing it under a Creative Commons license

- Visibility through different online platforms 